\title{
ANÁLISE DA UTILIZAÇÃO DE MODELOS DIFUSIVOS NA SECAGEM DE PIMENTA-DO-REINO PRETA (Piper nigrum L.)
}

\author{
D.A.S.ALVES, H. PERAZZINI, F. B. FREIREe J.T. FREIRE \\ Universidade Federal de São Carlos / Departamento de Engenharia Química \\ E-mail para contato: freire@ufscar.br
}

\begin{abstract}
RESUMO - A pimenta do reino preta é a mais importante especiaria comercializada mundialmente, sendo o Brasil um dos maiores produtores. Mesmo assim, poucos estudos para otimização do processo produtivo dessa commodity foram realizados. O objetivo desse trabalho foi realizar a caracterização da pimenta do reino e analisar a cinética de secagem. Com umidades variadas, mediram-se as dimensões lineares (diâmetro de Sauter e diâmetro médio), da área superficial, volume, esfericidade, e ainda a massa específica aparente e porosidade dos grãos. Os experimentos de cinética de secagem foram realizadosem camada fina, em um secador de convecção forçada com temperatura variando de 50 a $70^{\circ} \mathrm{C}$, e com velocidade do ar de 2,0 e 4,0 m/s. Com esses dados, fizeram-se ajustes das equações de Lewis, Page e Overhults, e do modelo Difusivo com hipóteses simplificadoras para a difusividade. Os resultados obtidos mostram que o modelo difusivo foi o mais adequado.
\end{abstract}

\section{INTRODUÇÃO}

A pimenta-do-reino é originária da Índia e, desde a década de 1930, quando foi introduzida no Brasil, por imigrantes japoneses, tem sido o suporte econômico de pequenos e grandes produtores da Região Amazônica(CHU,2006). O Brasil é o segundo maior exportador mundial dessa commodity, tendo os estados do Pará, Espírito Santo, Bahia, Paraíba e Maranhão como os maiores produtores nacionais, respectivamente (IBGE, 2013). Dependendo do processamento, a pimenta-do-reino pode ser manufaturada nas colorações verde, branca e preta, sendo a última resultado da colheita do fruto totalmente desenvolvido e posteriormente seco (CHU,2006). Dentre as etapas do processo produtivo, a secagem do material é fundamental para garantir a qualidade ao produto, diminuir a incidência de doenças e pragas, e auxiliar no processo de armazenamento e distribuição. (RAVINDRAN,2000)

A secagem de pimenta-do-reino em território brasileiro ocorre em sua maioria de duas maneiras distintas, utilizando secadores mecânicos ou secagem ao sol, sendo que em ambas as perdas são significativas. A escassez de trabalhos na literatura sobre a pimenta-do-reino, e mais especificamente sobre a secagem dessa especiaria aumenta a motivação por essa pesquisa.

O objetivo desse trabalho foi caracterizar os grãos de pimenta-do-reino e analisar o ajuste dos 
modelos de Page, Lewis, Overhults e Difusivo aos dados experimentais de curvas de secagem de pimenta-do-reino, e analisar também, a influência da temperatura e velocidade do ar no processo de secagem dos grãos de Piper Nigrum L.

\section{MATERIAL E MÉTODOS}

\subsection{Material}

A pimenta-do-reino (Piper Nigrum L.) utilizada foi fornecida pela empresa Sacconi Comércio Exportação e Beneficiamento de Produtos Agrícolas Ltda., situada ao norte do estado do Espírito Santo, na cidade de São Mateus.

\subsection{Métodos}

Peneiramento: Para a análise granulométrica empregou-se a técnica do peneiramento agitado utilizando o agitador da marca Retsch AS 200 control, a fim de se classificar uma massa conhecida de grãos utilizando peneiras com aberturas de diâmetro médio $\left(D_{i}\right) 3,35 \mathrm{~mm} ; 4,76 \mathrm{~mm} ; 4 \mathrm{~mm}$ e 3,35 mm da marca Tyler.Através da massa de sementes retidas em cada peneira calculou-se o diâmetro de Sauter $(\bar{D})$ de acordo com a equação 1 (FUMAGALLI, 2007).

$$
\bar{D}=\frac{1}{\sum_{i=1}^{n} x_{i} / D_{i}}
$$

Análise de Imagens: As imagens dos grãos de pimenta-do-reino foram obtidas com uma câmera digital Sony Cibershot DSC-WX50, com definição de 16,2 megapixels. Os grãos foram distribuídos sobre uma folha de papel milimetrado, distantes o suficiente para a análise. As imagens foram tiradas em triplicata em vários instantes do processo de secagem dos grãos estudados. Utilizou-se o software Image Pro Plus 6 para a análise das imagens, utilizando a distância de $1 \mathrm{~cm}$ como gabarito, para conversão de pixels em centímetros. As características do material determinadas pelo software foram o diâmetro médio (B), comprimento (L), largura (W) e espessura (T).Através dos dados obtidos, foi possível calcular o volume (V), área superficial (S), e esfericidade ( $\phi$ ) (MOHSENIN, 1986), respectivamente pelas equações 2,3 e 4 .

$$
V=\frac{\pi \cdot B^{2} \cdot L^{2}}{6(2 L-B)} \quad(2) \quad S \Leftrightarrow \frac{\pi \cdot B \cdot\left(4^{2}\right)}{2 L-B} \quad \phi=\frac{\sqrt[3]{W \cdot T \cdot L}}{L}
$$

Densidade de Bulk: A densidade de bulk $\left(\rho_{\mathrm{b}}\right)$, ou volumétrica, é dada pela relação entre a massa $(m)$ e o volume do leito empacotado $\left(V_{b}\right)$. Foram realizados ensaios em triplicata com auxílio de uma proveta de $250 \mathrm{ml}$.A amostra de partículas foi empacotada no leito com auxílio de um funil para derramar as sementes no interior do recipiente (PEREIRA, 2010). Para melhorar a acomodação dos grãos, algumas batidas na base do leito proveta foram efetuadas (ZOTIN,1985). Através da razão entre massa de partículas e o volume da proveta foi possível determinar a densidade de bulk pela 
equação 5 .

$$
\rho_{b}=\frac{m}{V_{b}}
$$

Através desses valores é possível calcular a porosidade do leito $\left(\varepsilon_{b}\right)$, que é dada pela relação entre o volume de vazios entre as partículas e o volume total do leito e se relaciona com a densidade de bulk e massa específica aparente $\left(\rho_{a p}\right)$ pela equação 6.

$$
\varepsilon_{b}=1-\frac{\rho_{b}}{\rho_{a p}}
$$

Picnometria: Para determinar a massa específica aparente $\left(\rho_{a p}\right)$, foi utilizada a técnica de picnometria líquida, utilizando tolueno, de acordo com a metodologia da AssociationofOfficialAnalyticalChemist, AOAC (2000), sendo obtidos a massa $(m)$ e volume dos grãos $\left(V_{a p}\right)$, determinando em seguida a massa específica aparente da pimenta-do-reino. Foram realizados quatro réplicas em cada ensaio.

$$
\rho_{a p}=\frac{m}{V_{a p}}
$$

Secagem em Camada Fina: O equipamento utilizado é apresentado com detalhes em Perazziniet. al. (2012). A pimenta-do-reino preencheu a célula de medida com diâmetro de $0,10 \mathrm{~m}$ e altura de $0,01 \mathrm{~m}$. O secador de convecção forçada foi ligado com uma célula idêntica acoplada, com o intuito de atingir o regime permanente (temperatura e vazão do ar constantes), sendo que, ao ser atingido, essa célula era substituída rapidamente pela célula contendo a amostra. O sistema permaneceu sob condições operacionais constantes de vazão e temperatura do ar de secagem. Neste trabalho serão apresentados apenas os dados de $50^{\circ} \mathrm{C}$, uma temperatura intermediária de $60^{\circ} \mathrm{C}$ e uma temperatura máxima de $70^{\circ} \mathrm{C}$. Para a velocidade do ar, testes iniciais indicaram que a velocidade do ar tinha pouca influência sobre a secagem, dessa maneira, foram escolhidos valores bem diferenciados de velocidade, sendo o valor mínimo de $2,0 \mathrm{~m} / \mathrm{s}$ e máximo de $4,0 \mathrm{~m} / \mathrm{s}$.A célula de secagem preenchida com a amostra foi pesada em intervalos de tempo pré-determinados em uma balança analítica da marca GEHAKA modelo BG400 com precisão de 0.001g. Após a pesagem, a célula era rapidamente acoplada ao secador, sendo esse procedimento realizado até que amassa entre duas amostragens fosse praticamente constante.Aos dados experimentais obtidos, ajustou-se os modelos de Page, Lewis, Overhults e Difusivo (através do software Matlab 7). Foram utilizados parâmetros estatísticos para análise de adequação dos modelos aos dados experimentais. Utilizou-se o software para calcular os valores da difusividade efetiva $\left(D_{e f)}\right.$. A obtenção desse parâmetro é mostrada em detalhes em Perazziniet. al. (2012).

\section{RESULTADOS E DISCUSSÃO}

\subsection{Peneiramento}

Os dados obtidos no experimento de peneiramento agitado estão apresentados no gráfico da figura 1 . 


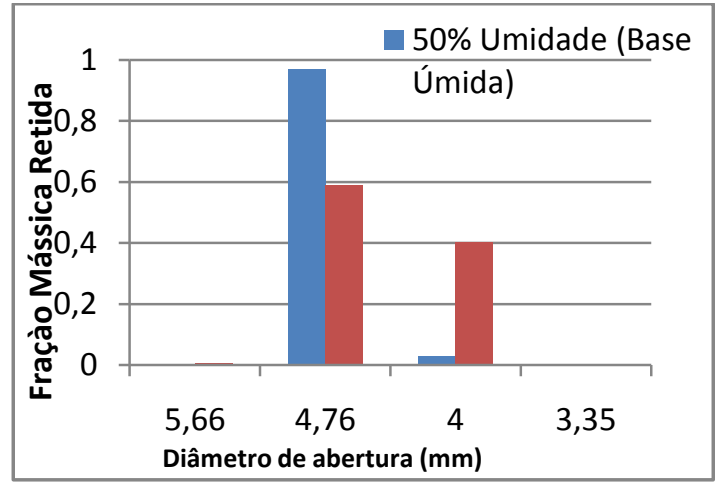

Figura 1- Fração mássica dos grãos retidos nas peneiras

De posse de tais dados, foi possível obter os dados do diâmetro de Sauter para as umidades de $10 \%$ e $50 \%$ em base úmida, respectivamente $4,42 \mathrm{~mm}$ e $4,73 \mathrm{~mm}$.

\subsection{Análise de Imagens}

Os dados podem ser observados na figura 2.

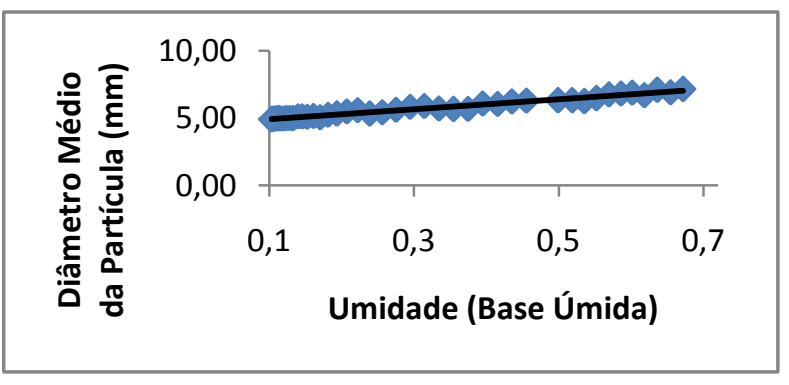

(a)

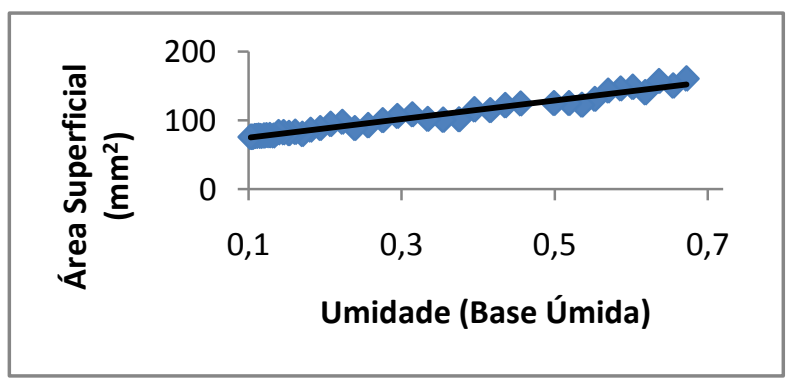

(c)

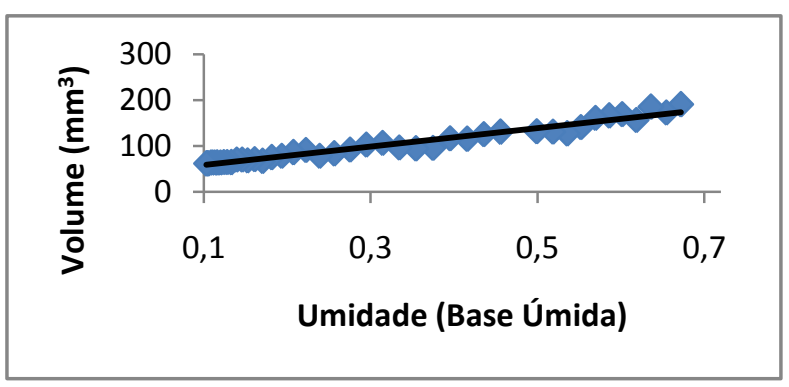

(b)

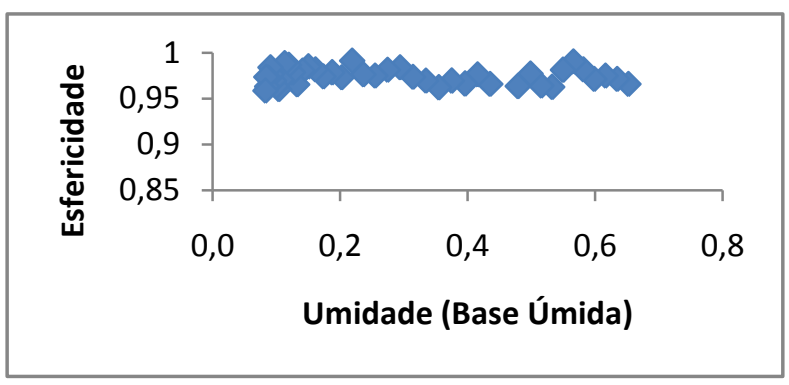

(d)

Figura 2-Características da pimenta do reino durante a secagem: (a) Diâmetro médio; (b) Volume; (c) Área Superficial; (d) Esfericidade.

Durante a secagem, em intervalos de $30 \mathrm{~min}$, amostras de 20 grãos era retiradas e através da 
análise de imagens, empregando as equações de 2 a 4, obteve-se a área superficial, volume e esfericidade da pimenta-do-reino preta, variando a umidade (Base úmida) de 8\% a 65\%..Pode-se observar que o diâmetro médio, o volume e a área superficial diminuíram com a redução da umidade em comportamento aproximadamente linear. Constatou-se que a esfericidade não obteve alteração significativa com a redução da umidade dos grãos como era esperado, mantendo a geometria esférica durante a secagem.

\subsection{Medidas de Densidade}

Após a realização dos experimentos de picnometria líquida em tolueno e testes em proveta, e posterior tratamento dos dados, obteve-se valores das densidades e porosidades do leito e da partícula, observados na tabela 1

Tabela 1 -Características físicas determinadas pelas medidas de densidade da partícula e do leito.

\begin{tabular}{|l|c|c|}
\hline \multicolumn{1}{|c|}{ Parâmetro } & $10 \%$ Umidade (Base Úmida) & $55 \%$ Umidade (Base Úmida) \\
\hline$\rho_{\mathrm{ap}}\left(\mathrm{g} / \mathrm{cm}^{3}\right)$ & 0,95 & 1,05 \\
\hline$\rho_{\mathrm{b}}\left(\mathrm{g} / \mathrm{cm}^{3}\right)$ & 0,62 & 0,70 \\
\hline$\varepsilon_{\mathrm{b}}$ & 0,35 & 0,34 \\
\hline
\end{tabular}

Para a variação de umidade de $10 \%$ a 55\% (Base Úmida), a densidade aparente e de bulk variaram pouco. $\mathrm{O}$ mesmo observou-se para a porosidade do leito.

\subsection{Secagem em Camada Fina}

Na figura 3a estão apresentadas as curvas experimentais de secagem da pimenta-do-reino preta, na faixa de temperatura de 50 a $70^{\circ} \mathrm{C}$. Pode-se observar, pela figura $3 \mathrm{a}$, que nos primeiros 100 minutos de experimento, a temperatura não exerce influência significativana secagem. Isso se deve ao fato da água retirada nestes instantes ser fracamente ligada ao substrato. Dessa forma, pequenas quantidades de energia são suficientes para a retirada da água do material. A partir de tal tempo, podese claramente observar que o tempo de secagem é menor para a temperatura de $70^{\circ} \mathrm{C}$, intermediário para $60^{\circ} \mathrm{C}$ e maior para $50^{\circ} \mathrm{C}$, ou seja, com o aumento da temperatura ocorreu diminuição do tempo de secagem,isto porque, com o aumento de $\mathrm{T}$, foi fornecida mais energia térmica ao processo.A cinética de secagem da pimenta-do-reino preta apresenta as mesmas características da maioria dos grãosagrícolas (ALMEIDA et al., 2009), ou seja, existe uma claradependência da velocidade da secagem com a temperatura doar. Segundo Peskeet al. (2003), a utilização de temperaturaselevadas permite uma secagem mais rápida, porém, podeprovocar diferença de teor de água entre a periferia e o centroda semente, gerando um gradiente de pressão possível decausar danificação mecânica. 


\section{9 a 22 de outubro de 2014 \\ Florianópolis/SC}

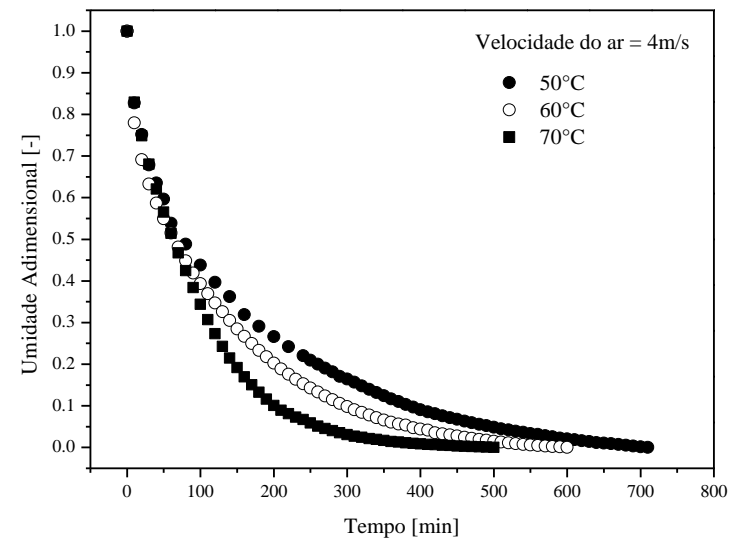

(a)

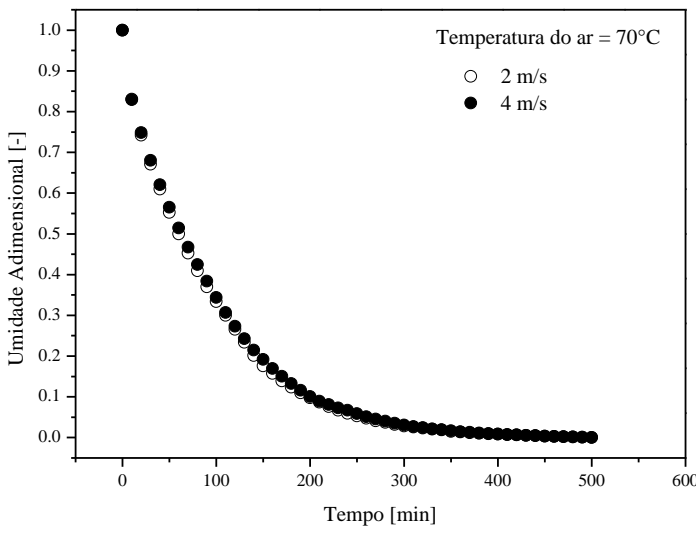

(b)

Figura 3-(a) Umidade adimensionalem função do tempopara temperaturas de 50,60 e $70^{\circ} \mathrm{C}$. (b) Umidade Adimensional durante a secagem de pimenta-do-reino preta para temperatura de $70^{\circ} \mathrm{C}$, a velocidade de $2 \mathrm{~m} / \mathrm{s}$ e $4 \mathrm{~m} / \mathrm{s}$.

A Figura 3b apresenta os dados de umidade adimensional (UA) em função do tempo de secagem, numa mesma temperatura $\left(70^{\circ} \mathrm{C}\right)$, para velocidade do ar de $2 \mathrm{~m} / \mathrm{s}$ e $4 \mathrm{~m} / \mathrm{s}$. De forma visual, observa-se que a velocidade do ar não exerce influência significativa no processo de secagem. Este efeito sugere que a resistência externa não influencia nas condições de operações utilizadas e que o controle da secagem da pimenta-do-reino depende da difusão interna de umidade nesse grão.

\subsection{Ajuste de Modelos}

Aos dados experimentais de secagem foram ajustados os modelos de Page, Lewis e Overhults e o Difusivo, podendo ser visualizados na figura 5.Os modelos estão apresentados em inúmeros trabalhos existentes na literatura, como por exemplo em Madamba et al(1996),Pereira (2010) e Perazzini et al (2012).Os resultados obtidos para as equações analisadas, sendo $\mathrm{R}^{2}$ o coeficiente de correlação e SE o erro médio estimado, foram, respectivamente: Lewis $(0,9967$ e 1,0816), Page $(0,9986$ e 0,0073$)$; Overhults $(0,9971$ e 0,0069$)$ e Difusivo $(0,9905$ e 0,0000003$)$.

Todos os modelos apresentaram ajustes satisfatórios à secagem de pimenta-do-reino, que forneceram resultados para os coeficientes de determinação superiores a 0,99. Madambaet al. (1996) ressaltam que o coeficiente de determinação $\left(\mathrm{R}^{2}\right)$,isolado, não é capaz de determinar satisfatoriamente o melhor modelo, sendo necessário analisar outros coeficientes. Sendo assim, o modelo Difusivo obteve, além do valor de $\mathrm{R}^{2}$ próximo da unidade, o menor valor do erro médio estimado, sendo o mais adequado nos ajuste aos dados experimentais. 


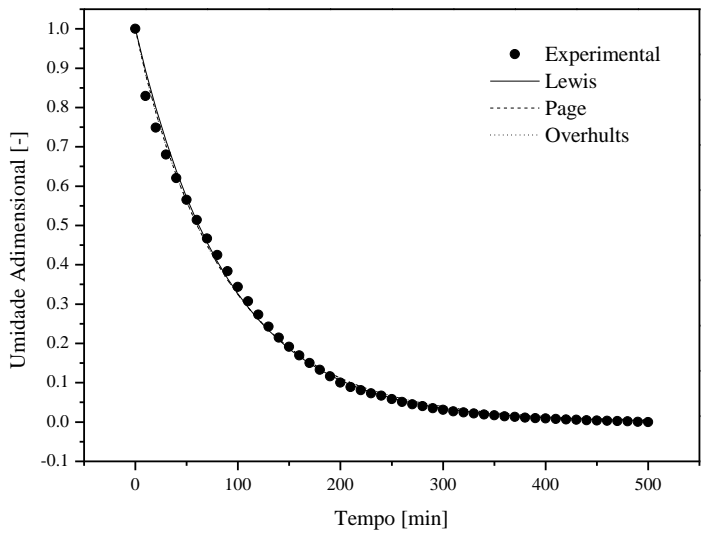

(a)



(b)

Figura 5 -(a) Umidade Adimensional durante a secagem de pimenta-do-reino preta e ajuste das equações de Lewis, Page e Overhults. (b) Umidade Adimensional durante a secagem de pimentado-reino preta e ajuste do Modelo Difusivo.

$\mathrm{Na}$ figura 5b, o modelo difusivo foi ajustado aos pontos experimentais de secagem. Pode-se observar também visualmente, além do $\mathrm{R}^{2}$ e do $\mathrm{SE}$, que o ajuste do modelo foi satisfatório para as temperaturas de 50,60 e $70^{\circ} \mathrm{C}$. Como esperado, os valores do coeficiente de difusividade efetiva determinados pelo modelo difusivo aumentaram com o aumento da temperatura.Tais valores são verificados na Tabela 2 .

Tabela 2- Valores da Difusividade Efetiva para a faixa de temperatura de secagem

\begin{tabular}{|c|r|}
\hline $\mathrm{T}\left({ }^{\circ} \mathrm{C}\right)$ & $\mathrm{D}_{\text {ef }}\left(\mathrm{m}^{2} / \mathrm{min}\right)$ \\
\hline 50 & $5,71 \times 10^{-8}$ \\
\hline 60 & $7,28 \times 10^{-8}$ \\
\hline 70 & $9,30 \times 10^{-8}$ \\
\hline
\end{tabular}

\section{CONCLUSÃO}

Nos ensaios de caracterização, constatou-se que o diâmetro médio, área superficial, perímetro e volume diminuem durante a secagem da pimenta-do-reino de forma linear, com encolhimento significativo do grão.Constatou-se também que a esfericidade não se altera com a variação do teor de umidade, mantendo a geometria esférica do grão.

Com base nos resultados obtidos, observa-se que nos 100 primeiros minutos a secagem não foi significativamente influenciada pela temperatura. A partir desse instante, a influência da temperatura foi muito significativa e a velocidade do ar de secagem não obteve influência relevante. Conclui-se assim que o mecanismo que controla a secagem é a difusão interna.

Como esperado, os valores da difusividade efetiva obtidos aumentaram com o aumento da temperatura do ar de secagem de $5,71 \times 10^{-8} \mathrm{~m}^{2} / \mathrm{min}$ a $50^{\circ} \mathrm{C}$ para $9,30 \times 10^{-8} \mathrm{~m}^{2} / \mathrm{mina} 70^{\circ} \mathrm{C}$. 
Através de análise estatística, todos os modelos ajustados obtiveram ajustes significativos na cinética de secagem. Dentre eles, o modelo Difusivo forneceu melhor ajuste aos dados experimentais.

\section{REFERÊNCIAS}

ALMEIDA, D. P.; RESENDE, O.; COSTA, L. M.; MENDES, U. C.; SALES,J. F. Cinética de secagem do feijão adzuki (Vignaangularis).Global Science and Technology, v.2, p.72-83. 2009. AOAC. Official Methods of Analysis of AOAC Intl, $17^{\text {th }}$ ed. Arlington, VA, USA: Association of oficialAnalutical Communities. 2000.

CHU, E.Y., et al. A cultura da pimenta do reino. Brasília: EMBRAPA: 2.ed., 2006.

FUMAGALLI, F. Estudo da secagem das sementes deBrachiarabrizantha.2007. 149 f. Tese (Doutorado em Engenharia Química) - UFSCar, São Carlos, 2007.

IBGE. Instituto Brasileiro de Geografia e Estatística. Levantamento Sistemático da Produção Agrícola:Pesquisa Mensal de Previsão e Acompanhamento das Safras Agrícolas no Ano Civil.Rio de Janeiro: IBGE, v.26 n.1 p.1-83. Janeiro. 2013.

MADAMBA, P. S.; DRISCOLL, R. H.; BUCKLE, K. A. The thin layer drying characteristic of garlic slices. Jornal of Food Engineering, v.29, p.75-97, 1996.

MOHSENIN, N. N. Physical properties of plant and animalmaterials.New York: Gordon andBreachPublishers. 841 p., 1986.

.Perazzini, H. ; FREIRE, Fábio Bentes ; FREIRE, J. T. . Secagem de resíduos citricos em camada delgada: estudo da difusão de umidade. In: Congresso Brasileiro de Engenharia Química (COBEQ), 2012, Búzios-RJ. Anais do Congresso Brasileiro de Engenharia Química. São CarlosSP: Editora Cubo, 2012.

PEREIRA, A.V. Caracterização e secagem de sementes de painço (SetariaitalicaL.) 2010. $92 \mathrm{f}$. Dissertação (Mestrado em Engenharia Química) - São Carlos, UFSCar, 2010.

PESKE, S. T.; VILLELA, F. Secagem de sementes. In: PESKE, S. T.; ROSENTHAL, M.; ROTA, G. R. M. Sementes: Fundamentos científicos e tecnológicos. Pelotas: Editora e GráficaUniversitária (UFPel). p.283-322. 2003.

RAVINDRAN, P. N.; et al. Indian J. Arecanut Spices and Medicinal Plants.v. 2, p. 71-78, 2000. ZOTIN, F.M.Z. O efeito de parede em colunas de recheio. 1985. 85 f. Dissertação (Mestrado em Engenharia Química) - São Carlos, UFSCar, 1985. 